bike vs car $(69 \%)$, car vs car $(8 \%)$ while in $6 \%$ motorbike vs motorbike or with Qingqis. In non-fatal accidents $(\mathrm{n}=178)$ majority were due to car (82\%).

Conclusion From the above results we can conclude that numbers of RTI has been decreasing in the post-ban policy period. These results indicate strong impact of three wheelers on RTI in our part of world which can be control by enforcing banning of such transport. In order to sustain these countermeasures over time, awareness about safety measures is the key element. Next, law enforcement agencies should be strengthen along with that government should provide alternate modes of transportation options for public in the form of mass transport.

\section{RESULTS OF AN IN-DEPTH ANALYSIS OF HIGHWAY ROAD CRASHES IN KOLAR DISTRICT, KARNATAKA, INDIA}

Gopalkrishna Gururaj. Department of Epidemiology, WHO CC for Injury Prevention, National Institute of Mental Health and Neuro Sciences, Bangalore, India

\subsection{6/injuryprev-2016-042156.883}

Background Highways account for a major share of travel and transport in India and many other LMICS. Road deaths and injuries are also significantly high on these highways due to different transport characteristics as compared to other roads. Despite this, the burden and pattern of highways crashes are not clearly known to develop sustainable interventions.

Methods The burden, pattern, characteristics and outcomes of highway road crashes was delineated using combined data from police and hospital sources. Using mixed method approaches, comprehensive resource mapping, facilities inventory, discussion with stake holders, environmental scanning and identifying characteristics of high risk crash locations was completed.

Results Road Traffic Injuries (RTIs) contributed for 39\% of fatal and $34 \%$ of non-fatal injuries in the district. In 2014, 280 fatal road crashes were registered resulting in death of 336 persons. In the same period, 596 non fatal crashes were registered with police resulting in injuries among 1213 persons with a ratio of 1:4 between deaths and injuries. Information from just 2 major hospitals revealed that 8518 RTIs were registered in this period, indicating huge underreporting in police records. The 2 national highways and 5 state highways contributed for $37 \%$ and $25 \%$ of total road deaths, respectively, with $32 \%$ of nonfatal crashes occurring on both highways.. Males, 16-45 years, two wheeler riders and pedestrians were involved in high number of crashes. Collision patterns indicated a greater involvement of heavy vehicles like buses and trucks along with motor cars on highways. Nearly $43 \%$ died at the crash site and remaining deaths occurred on the way to hospital or in the hospital. Use of helmets- seat belts was extremely low and drink driving was recorded among $18.5 \%$ of hospitalised RTIs. Excessive speeding was a major cause of crashes as informed in focussed group discussions. Several high risk crash locations were identified and possible human, vehicle and road related factors delineated. Injuries to head and face along with extremity injuries were most frequent and both prehospital and inhospital care had several limitations and deficiencies.

Conclusions Safety of all road users and especially vulnerable road users should be given greater importance on highways with implementation of well proven countermeasures along the five pillars of road safety in India and other LMICs.

\section{SLOW-MOVING AGRICULTURAL VEHICLES IN TRAFFIC}

Veli-Matti Tuure, Markku Lätti, Eerikki Kaila. Work Efficiency Institute (TTS), Finland

10.1136/injuryprev-2016-042156.884

Background Along with structural changes in agriculture, increasing area of arable land and the number of field parcels on a farm are exceedingly raising the movement of agricultural equipment on public roads. At the same time also the sizes of agricultural vehicles are growing. Traffic accidents involved agricultural vehicles often lead to serious injuries or even death.

Methods In order to find out the present situation in traffic accidents and to improve the traffic safety with slow-moving agricultural vehicles, national statistical information of road accidents 2004-2013 and of occupational accidents in agriculture 20042014 were gathered. In addition, an enquiry of road accidents, near accidents and safety measures (good practices) was sent to large farms. In order to find out how much time is spend and how many kilometres are driven on public roads by a farm tractor on a large farm, two tractors on two farms were followed by AgriSmart GPS system during a growing season.

Results For results about 6300 roads accidents are analysed. Most often the agricultural party was a tractor and the other party a passenger car, as reported also in previous studies. The speed limit of the road was at least $80 \mathrm{~km} / \mathrm{h}$ in more than half of the accidents (54\%). Turning accidents were the most common type of these accidents. More than $20 \%$ of respondents of the enquiry had had at least one road accidents with slow-moving agricultural vehicles during the last 10 years. The most serious accidents occurred on main roads where variations in vehicle velocities are the largest. The farms have put into practice several measures - most often technical like extra lights, flashing lights and wide private crossroads - to improve traffic safety. According to the first half of the follow-up period of the two tractors, the tractors were used on roads about $20 \%$ of the time.

Conclusions Wide variations in vehicle velocities and poor ability to recognise slow-moving agricultural vehicles are crucial risk factors in agricultural traffic. Various measures are needed to reduce traffic accidents involved slow-moving agricultural vehicles. These should be focused on agricultural machinery, roads, farmers and other road users. This on-going study is financed by the Farmers' Social Insurance Institution and the Finnish Research Fund of Agricultural Machinery.

\section{SAFE SCHOOLS PROJECT, SOUTH AFRICA}

PP Mtambeka, AB Van As ,Ca Mavengere, A Van Niekerk, G Elliot, R Mcinerney. Childsafe South Africa, Red Cross Children's Hospital

\subsection{6/injuryprev-2016-042156.885}

Background The World health Organisation indicates that child pedestrian injuries are highest in African countries with a continental mortality rate that is twice the global world (WHO 2011). In South Africa it is noted that the majority of children walk to and from school, placing them at particular risk to road traffic crashes resulting in injury, disability or death(Stats SA 2013) Child pedestrians are particular vulnerable to road crashes due to their physical and cognitive limitations.

Methods The Safe School project aimed to reduce child pedestrian injuries and deaths in South Africa by introducing the iRAP star rating concept, which provides tools and training to help countries make roads safe by inspecting high-risk roads and 
developing star ratings for those roads, with the ultimate goal of eliminating one- and two-star rated roads from the world's road network. 3 primary schools were selected in South Africa where intervention took place and 1 school served as a control for monitoring and evaluation purposes.

Results The pilot project has developed an innovative model combining education for the school children, training for teachers and advocacy action to catalyse the introduction of safe road infrastructure. It has also enabled creation of a multi-stakeholder partnership and further contributed to development of educational tool kit by Takalani Sesame (Sesame Street).

The project has been successful in one of its primary objectives to encourage the government to ensure sustained investments for safer roads thorough collaboration with City of Cape Town road engineers.

Conclusion The project has been effective as a model for catalysing sustainable investment in interventions aimed to improve road safety for school children. This model has the potential to be replicated on a wider basis across other schools in South Africa and other countries.. With its outcomes and potential long term impact, it has already made valuable contribution to the Decade of Action for Road Safety and has the potential to do so.

\section{THE SOCIAL DETERMINANTS OF TRAFFIC-RELATED INJURIES AMONG ADOLESCENTS}

1,2 Mohamed Mouloud Haddak. 'University of Lyon, France; ${ }^{2}$ Ifsttar-Umreste, France

10.1136/injuryprev-2016-042156.886

Background Youngster injury is the leading cause of mortality, morbidity and permanent disability in adolescent in the developed world. The objective of this research is to study the joint effect of family and contextual socioeconomic characteristics of teenagers on their risk of road accidents, taking into account their mobility practices, their behaviour and their attitude to risk.

Methods A case-control study was conducted on a population of 601 young people aged 14-17, in 2013. Cases (208 subjects) were selected from the Rhône Road Trauma Registry. Controls (393 subjects) adjusted by age and sex were randomly selected by telephone. L'exposition à la circulation routière est mesurée pour chaque mode de transport utilisé par le budget-temps. The relationships between SES status, urban/periurban-rural location, mode of transport, mobility practice, and injury type were determined using conditional logistic regression. Exposure to road traffic is measured for each mode of transportation used by the weekly time budget.

Results The intensive use of motorised two-wheelers holds an essential role in the risk of road accidents between 14 and 17 years $(\mathrm{OR}=4.1[2.3-7.2])$, followed by regular cycling $(\mathrm{OR}=3.6[2.0-6.5])$ and skating $(\mathrm{OR}=1.9$ [1.1-3.1]). Socioeconomic status of young people is highlighted: students in professional college or young apprentices are at higher risk $(\mathrm{OR}=2.1[1-4.3])$. Compared with urban adolescents, adolescents living in rural areas suffer a 1.9 higher risk (1.9 [1.2-3.0]). The links between road risk behaviour and smoking are also underlined (OR $=4.4$ [2-9.7]).

Conclusions These results show that adolescent road traffic injury in Rhône is a major health concern, especially among motorcyclist males (40\% of the injuries) from rural area and from lower SES. But this study also shows the significant impact of behavioural factors (tobacco, cannabis) on the risk of accident.

\section{ANALYSING THE OFFENDER DRIVER BEHAVIOUR: RECIDIVISM, JUST THE TIP OF THE ICEBERG?}

${ }^{1} \mathrm{C}$ Castro, ${ }^{1} \mathrm{~A}$ Gugliotta, ${ }^{1} \mathrm{P}$ García-Fernández, ${ }^{2} \mathrm{P}$ Ventsislavova, ${ }^{1} \mathrm{E}$ Esiman, ${ }^{2} \mathrm{D}$ Crundall. ${ }^{1}$ University of Granada, Spain; ${ }^{2}$ Nottingham Trent University, UK

\subsection{6/injuryprev-2016-042156.887}

Background The Subjective Risk Estimation (SER) depends on the own driving skills self- assessment and the calibration made between the benefits and cost involved in this risk at the moment of driving. Offender drivers' assumption of higher risk could be related with a more general factor that also involves the assumption of higher risk in other facets of their lives that could derive in drugs taking or other kind of additions. Deficient SER could be considered as a TRAIT, a higher proneness or disposition that only some drivers could show as another characteristic of their personality (measured with the DOSPERT (Domain-Specific Risk Taking). It could also be possible to establish a relation with other personality measures related to Anger or Aggressive Driving, measured with DAS (Driving Anger Scale).

Methods The Subjective Risk Estimation (SER) is measured with the DOSPERT (Domain-Specific Risk Taking Scale). The Anger to Aggressive Driving is measured with DAS (Driving Anger Scale).

Results In this work we would like to find out if could deficient SER be considered as a TRAIT of personality and some drivers could show a higher proneness to it (i.e. offender drivers) and if does deficient SER take part of a more general pattern of behaviour related with risk behaviour (drugs taking, alcohol consumption, and addiction to food or sex) that should be also trait to sort the problem out. Results are in progress.

Conclusions This knowledge could be useful to better understand the different profiles of drivers. To plan prevention and to settle better strategies of intervention and treatment of the specific lacks for each group of drivers, for instance, reducing aggressive driving or helping to be aware of the problem and dealing with the Anger in offender drivers.

\section{\begin{tabular}{|l|l}
888 & ROAD TRAFFIC INJURIES IN CROATIA
\end{tabular}}

Ivana Brkic Bilos, Maja Silobrcic Radic, Verica Kralj, Tanja Coric. Croatian Institute of Public Health, Croatia

\subsection{6/injuryprev-2016-042156.888}

Background The objective of this paper was to analyse mortality and morbidity from road traffic injuries in Croatia, as a contribution to the awareness of this public health.

Methods The data used in the research was collected from the routine mortality and morbidity statistics, Ministry of Interior Data, European Health for All Database, as well as from the results of the Global Status Report on Road Safety 2015 (GSRRS).

Results Traffic accidents and their consequences are still a serious public health problem in Croatia. They are the leading cause of child and youth mortality and the leading cause of premature deaths within the injuries group. Croatia has lately reported a noteworthy drop in road fatalities, despite the increase in number of drivers, motor vehicles and roads. According to the Ministry of Interior data, the road traffic injury (RTI) mortality rate for Croatia in 2005 was $13.4 / 100.000$, only to drop to $7.3 / 100.000$ in 2014. Injuries incurred in traffic accidents account for $21.3 \%$ of all injury-related hospitalizations in 2014. Croatia has achieved sustained reductions in traffic-related injuries and fatalities through effective road safety program and good level of 